13

\title{
Электрические свойства тонких пленок аморфного углерода, полученных методом ионно-лучевого напыления
}

\author{
(C) Ю.Е. Калинин, М.А. Каширин, В.А. Макагонов, С.Ю. Панков, А.В. Ситников
}

Воронежский государственный технический университет, 394026 Воронеж, Россия

e-mail: Kalinin48@mail.ru

(Поступило в Редакцию 14 марта 2017 г.)

Исследованы электрические свойства тонких пленок аморфного углерода, полученных методом ионно-лучевого распыления графитовой мишени в атмосфере аргона. Анализ структуры методом рамановской спектроскопии показал, что полученные тонкие пленки можно классифицировать как графитоподобные. Изучение электрической проводимости и термоэдс показали, что с повышением температуры от 77 до $190 \mathrm{~K}$ в полученных тонких пленках прыжковый механизм электрической проводимости с переменной длиной прыжка по локализованным состояниям вблизи уровня Ферми сменяется прыжковым переносом по ближайшим соседям, а в области температур, близких к комнатной, электроперенос осуществляется прыжками переменной длины по локализованным состояниям в хвосте валентной зоны.

DOI: 10.21883/JTF.2017.11.45137.2248

\section{Введение}

Физические свойства аморфных твердых тел продолжают привлекать значительное внимание как теоретиков, так и экспериментаторов. Такое внимание обусловлено тем, что если кристаллические твердые тела достаточно хорошо изучены, то аморфную структуру пока не удается описать однозначно, а следовательно, предсказать физические свойства материала с такой структурой. С другой стороны, аморфное состояние является неравновесным и часто обнаруживает постепенный или даже быстрый переход в более равновесное состояние, следствием чего в аморфных образцах часто имеет место необратимое изменение электрических свойств, особенно при повышении температуры [1]. Аморфный углерод с этой точки зрения представляет особый интерес, поскольку является однокомпонентным и при распылении в вакууме может быть сформирована тонкая пленка с аморфной структурой. Структура тонких пленок аморфного углерода была подробно исследована в [2-4]. Было показано, что пленки представляют собой смесь двух фаз: алмазоподобной с $s p^{3}$-типом гибридизации атомов углерода, тетрагональной структурой и графитоподобной, характеризующейся $s p^{2}$-типом гибридизации атомов углерода, при этом графитоподобная фаза формирует так называемые $s p^{2}$-кластеры, которые характеризуются размером от единиц до нескольких десятков нанометров [5,6].

В зависимости от соотношения атомов углерода с $s p^{2}$ - и $s p^{3}$-типами гибридизации электрические свойства полученных тонких пленок могут изменяться от полуметаллических, характерных для графита, до диэлектрических, как у алмаза [7-9]. Так, ширина запрещенной зоны тонкой пленки аморфного углерода может принимать значения от 0.5 до $4 \mathrm{eV}$ [10], а удельное электрическое сопротивление изменяться от $10^{-3}$ до $10^{12} \Omega \cdot \mathrm{cm}[11-14]$
Условия роста, такие как скорость осаждения, температура подложки, наличие реактивных газов или присутствие легирующих добавок, значительно влияют на соотношение $s p^{2} / s p^{3}$-связей в пленках. Из всех разновидностей тонких пленок аморфного углерода наиболее интересными и изученными являются тонкие пленки алмазоподобного аморфного гидрогенизированного углерода $\alpha$-С:Н. Водород при напылении не только заполняет оборванные связи, понижая число электронных состояний собственных дефектов, но также способствует образованию $s p^{3}$-связей $[6,15]$. В работе [16] исследовалось легирование тонких пленок $\alpha$-С:H фосфором. Концентрация фосфора изменялась от 1 до 7 at.\%, при этом у пленок, содержащих 1 at.\% фосфора, электрическое сопротивление возрастает, а при дальнейшем увеличении содержания фосфора до 5 at.\% происходит монотонное уменьшение электрического сопротивления пленок. Из анализа полученных зависимостей, а также результатов рамановской спектроскопии авторы сделали вывод, что легирование фосфором выше 5 at.\% приводит к графитизации структуры пленок $\alpha$-C:H $\langle\mathrm{P}\rangle$.

В работах $[17,18]$ изучались свойства пленок аморфного гидрогенизированного углерода, модифицированных нанокластерами платины $\alpha$-C:H $\langle\mathrm{Pt}\rangle$. Авторы также пришли к выводу, что добавление $\sim 5$ at.\% Pt приводит к графитизации матрицы пленок $\alpha-\mathrm{C}: \mathrm{H}\langle\mathrm{Pt}\rangle$, обусловленной ее взаимодействием с нанокластерами платины. Отметим, что аналогичные изменения структуры матрицы пленок $\alpha$-С:Н наблюдались в [19] при модификации $\alpha$-С:Н кобальтом. Также аналогичный эффект, но в более слабой форме наблюдался и при модификации матрицы аморфного углерода атомами серебра $[20,21]$.

В настоящей работе исследованы электрические свойства тонких пленок аморфного углерода, полученных методом ионно-лучевого напыления в атмосфере аргона, и влияние низкотемпературной термической обработки на их электрические свойства. 


\section{Методика эксперимента}

Для получения тонких аморфных пленок углерода применялся метод ионно-лучевого распыления графитовой мишени в атмосфере аргона с давлением $P_{\mathrm{Ar}}=3.6 \cdot 10^{-4}$ Torr и последующего осаждения материала на ситалловую подложку, находящуюся при комнатной температуре [22]. Толщина полученных пленок измерялась на интерферометре МИИ-4 и оказалась равной $2.5 \mu \mathrm{m}$.

Структуру исследовали методами дифракции рентгеновских лучей на дифрактометре Bruker D2 Phaser и методом комбинационного (рамановского) рассеяния на спектрометре Horiba LabRAM HR Evolution в геометрии обратного рассеяния при возбуждении на длине волны $532 \mathrm{~nm}$ в неполяризованном свете.

Зависимости удельного электрического сопротивления от температуры были измерены двухзондовым методом на постоянном токе при помощи универсального цифрового мультиметра В7-78/1. Зависимости термоэдс пленок от температуры получены дифференциальным методом. Материалом холодного и горячего зондов служила серебряная проволока чистотой 99.99\%. Относительная погрешность измерения электрического сопротивления исследуемых тонких пленок не превышала $2 \%$, а термоэдс $-3 \%$.

Термообработку и измерение зависимостей удельного электрического сопротивления от температуры проводили в вакууме с давлением остаточных газов не более $5 \cdot 10^{-5}$ Torr. Скорость роста температуры и скорость охлаждения составляла $2-3 \mathrm{~K} / \mathrm{min}$.

Из картин дифракции рентгеновских лучей следует, что исследованные тонкие пленки являются аморфными как в исходном состоянии, так и после термообработки при $T=200^{\circ} \mathrm{C}$ в течение $60 \mathrm{~min}$ (рис. 1).

Наиболее распространенным способом анализа структуры аморфных углеродных материалов является рамановская спектроскопия. На рис. 2 представлены рамановские спектры для тонких пленок аморфного углерода

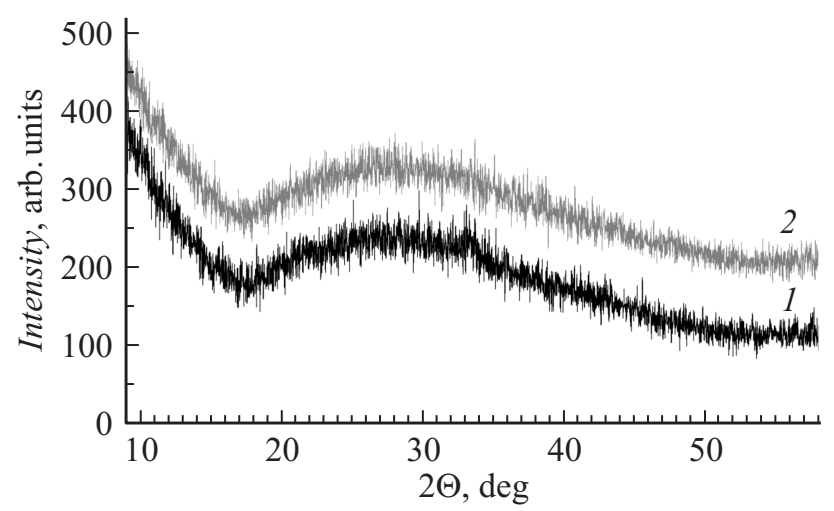

Рис. 1. Картины дифракции рентгеновских лучей $\left(\lambda_{\mathrm{CuK \alpha 1}}=\right.$ $=1.54 \AA$ ) для тонких пленок аморфного углерода в исходном состоянии (кривая 1) и после термообработки в вакууме при $T=200^{\circ} \mathrm{C}$ в течение $60 \mathrm{~min}$ (кривая 2).
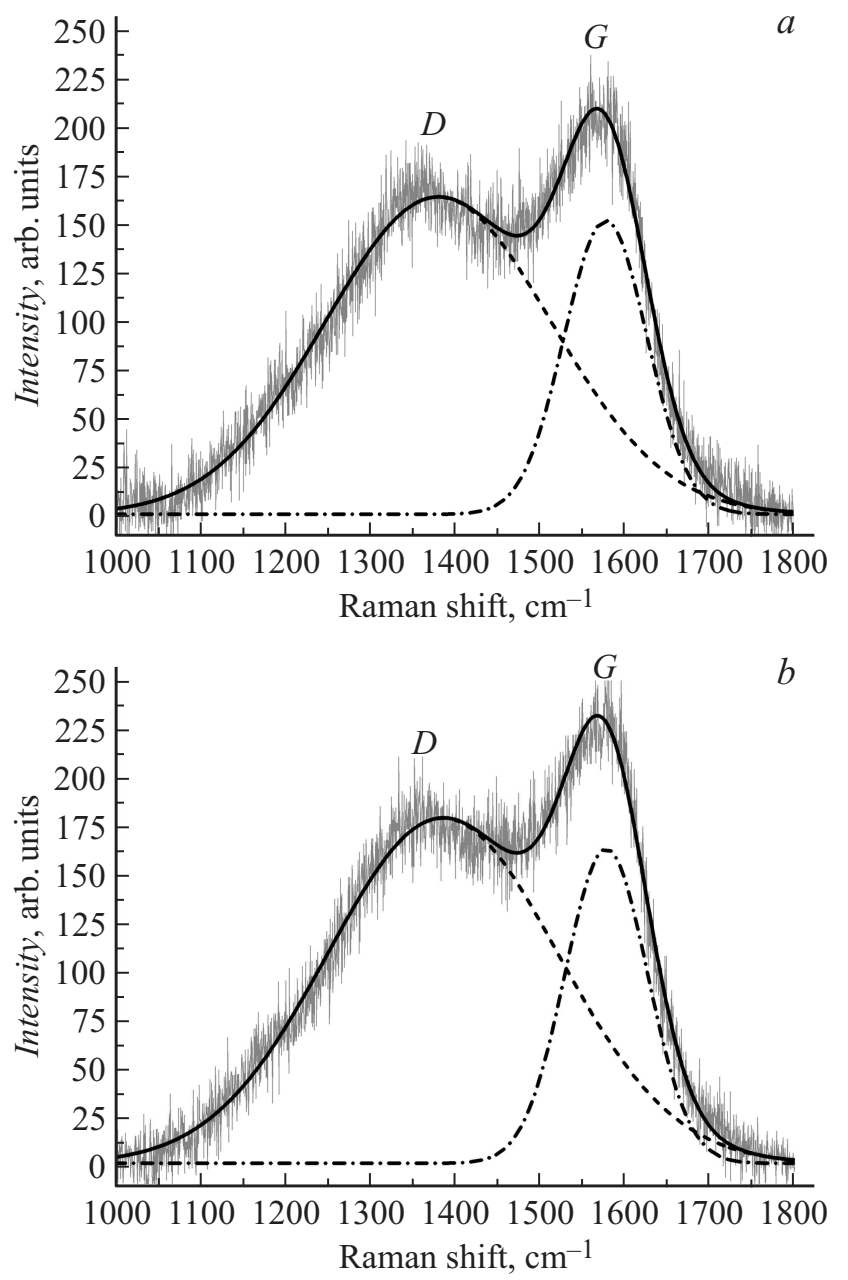

Рис. 2. Рамановские спектры для тонких пленок аморфного углерода в исходном состоянии $(a)$ и после термообработки в вакууме при $T=200^{\circ} \mathrm{C}(b)$.

в исходном состоянии $(a)$ и после термообработки в вакууме при $T=200^{\circ} \mathrm{C}(b)$. На полученных спектрах наблюдаются две полосы: $D$-полоса, обусловленная растяжением (stretching modes) пар $s p^{2}$-связей в углеродных кольцах и цепях, с частотой около $1380 \mathrm{~cm}^{-1}$, и $G$-полоса, вызванная „дышащими“ модами (breathing modes) в углеродных цепях, с частотой около $1580 \mathrm{~cm}^{-1}$, что является типичным для аморфного углерода [23]. Разложение спектров на две гауссовы компоненты позволяет определить положения максимумов $D$ - и $G$-полос и значения ширины пиков на их полувысоте (табл. 1). Из анализа положения пика $G$ и отношения интенсивностей полос $D$ и $G\left(I_{D} / I_{G}\right)$ согласно градуировкам, приведенным в [24], было установлено, что содержание $s p^{3}$-гибридизированного углерода не превышает $7 \%$. Следовательно, полученные тонкие пленки можно отнести к графитоподобным.

Значения ширины пика $G$ на половине высоты больше $50 \mathrm{~cm}^{-1}$, что свидетельствует о том, что размер областей $s p^{2}$-гибридизированного углерода менее $2 \mathrm{~nm}$ [24], а следовательно, для точной оценки размеров класте- 
Таблица 1. Параметры спектров рамановского рассеяния для тонких пленок аморфного углерода в исходном состоянии и после термообработки в вакууме при $T=200^{\circ} \mathrm{C}$, а также значения средних размеров кластеров $s p^{2}$-гибридизированного углерода $\left(l_{a}\right)$

\begin{tabular}{l|c|c|c|c|c|c}
\hline \multicolumn{1}{c|}{ Состояние } & $\begin{array}{c}\text { Положение } \\
\text { пика } D, \mathrm{~cm}^{-1}\end{array}$ & $\begin{array}{c}\text { Ширина пика } D \\
\text { на половине } \\
\text { высоты, } \mathrm{cm}^{-1}\end{array}$ & $\begin{array}{c}\text { Положение } \\
\text { пика } G, \mathrm{~cm}^{-1}\end{array}$ & $\begin{array}{c}\text { Ширина пика } G \\
\text { на половине } \\
\text { высоты, } \mathrm{cm}^{-1}\end{array}$ & $I_{D} / I_{G}$ & $l_{a}, \mathrm{~nm}$ \\
\hline $\begin{array}{l}\text { Исходное } \\
\text { После отжига } \\
\text { в вакууме при } 200^{\circ} \mathrm{C}\end{array}$ & 1382 & 313.6 & 1579 & 114.8 & 1.08 & 1.4 \\
\hline
\end{tabular}

ров можно применить модель $[17,25]$, согласно которой средний размер кластеров $s p^{2}$-гибридизированного углерода $l_{a}$ связан с величиной $I_{D} / I_{G}$ отношением $I_{D} / I_{G}=\gamma l_{a}^{2}$, где $l_{a}$ - размер кластера, $\gamma=5.5 \cdot 10^{-3} \AA^{2}$. Оценки размеров кластеров показали, что для изученных пленок аморфного углерода $l_{a} \approx 1.4 \mathrm{~nm}$, что совпадает со средним размером кластера, образованного $s p^{2}$-гибридизированным углеродом согласно литературным данным [26,27].

\section{Результаты эксперимента и их обсуждение}

Значения удельного электрического сопротивления и термоэдс при комнатной температуре для полученных тонких пленок углерода составили $101.2 \mu \Omega \cdot \mathrm{m}$ и $12.2 \mu \mathrm{V} / \mathrm{K}$ соответственно. Знак термоэдс - положительный, что указывает на дырочный тип проводимости. После отжига в течение $60 \mathrm{~min}$ в вакууме при температуре $200^{\circ} \mathrm{C}$ удельное электрическое сопротивление пленки, измеренное при комнатной температуре, понижается до значения $81 \mu \Omega \cdot \mathrm{m}$. При этом термоэдс осталась положительной, но абсолютная величина уменьшилась и стала равной $8.6 \mu \mathrm{V} / \mathrm{K}$.

Для установления механизмов электропереноса, а также оценки влияния термического отжига на удельное электрическое сопротивление и термоэдс в полученных тонких пленках аморфного углерода были исследованы их температурные зависимости в диапазоне $77-300 \mathrm{~K}$ (рис. 3, $a$ и $b$ ). Из рис. 3, $a$ видно, что с понижением температуры до $77 \mathrm{~K}$ значения удельного электрического сопротивления как для образца в исходном состоянии (кривая 1 , рис. $3, a)$, так и для отожженного (кривая 2, рис. $3, a)$ увеличиваются в 3 и 2 раза соответственно.

Совместный анализ данных рис. 3 показал, что в области температур 77-130 K удельное электрическое сопротивление и термоэдс спрямляются в координатах $\ln R \propto f\left(1 / T^{1 / 4}\right)$ и $S \propto f\left(1 / T^{1 / 2}\right)$ (рис. 4$)$, что указывает на прыжковый механизм проводимости электронов с переменной длиной прыжка по локализованным состояниям, лежащим в узкой полосе энергий вблизи уровня Ферми. Тогда, согласно [11], выражение для электриче-
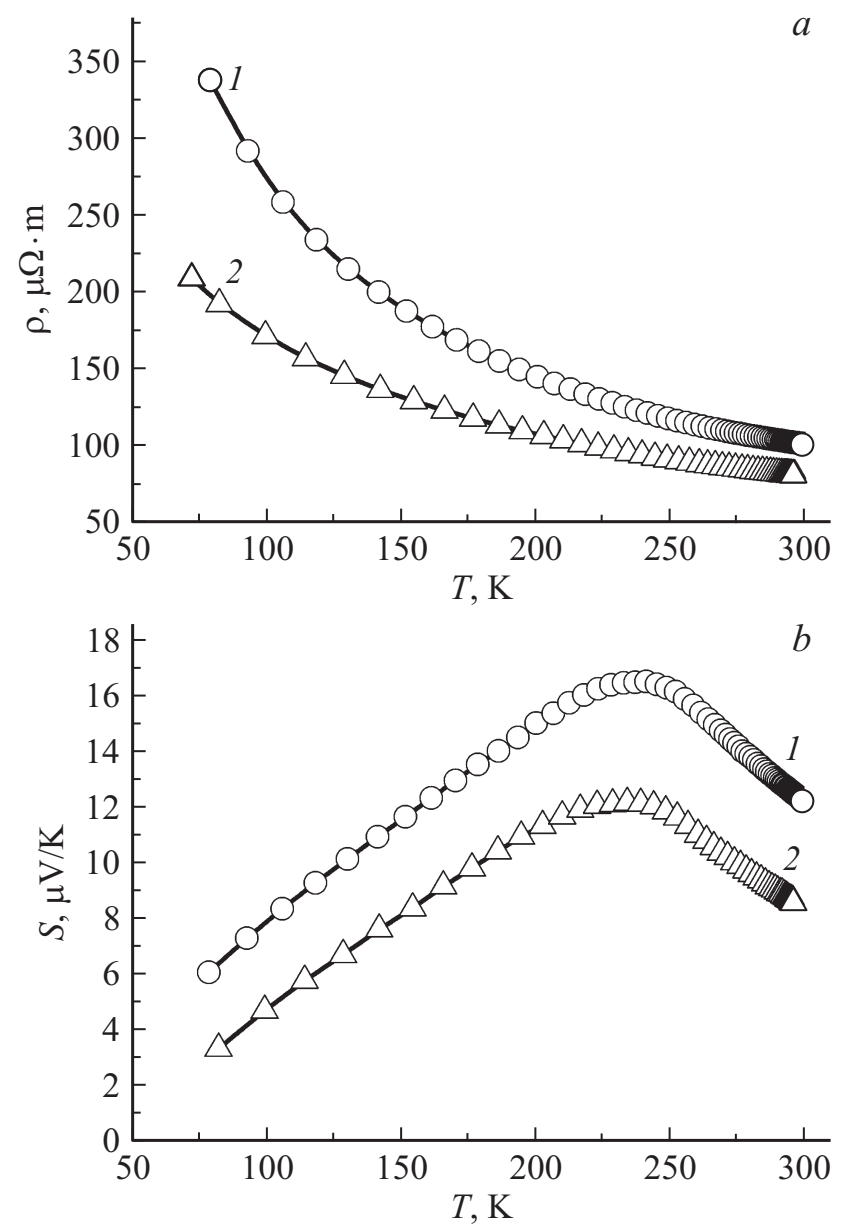

Рис. 3. Зависимости удельного электрического сопротивления $(a)$ и термоэдс $(b)$ тонких пленок аморфного углерода С от температуры в диапазоне $77-300 \mathrm{~K}$ : кривая $1-$ исходное состояние, кривая 2 - после отжига в вакууме при $200^{\circ} \mathrm{C}$.

ской проводимости имеет следующий вид:

$$
\sigma=e^{2} R^{2} v_{p h} g \exp \left(-\frac{B}{E}\right)^{1 / 4}
$$

где

$$
\begin{gathered}
B=\frac{16}{a^{3} k g\left(E_{F}\right)}, \\
R=\left[\frac{3}{2 \pi a g\left(E_{F}\right) k T}\right]^{1 / 4},
\end{gathered}
$$


Таблица 2. Рассчитанные параметры для пленок аморфного углерода, определенные из модели прыжковой проводимости электронов с переменной длиной прыжка по локализованным состояниям, лежащим в узкой полосе энергий вблизи уровня Ферми

\begin{tabular}{l|c|c|c|c|c|c|c}
\hline \multicolumn{1}{c|}{ Состояние } & $B^{1 / 4}, \mathrm{~K}^{1 / 4}$ & $B, \mathrm{~K}$ & $g\left(E_{F}\right), 1 /\left(\mathrm{eV} \cdot \mathrm{cm}^{3}\right)$ & $R$ при $120 \mathrm{~K}, \mathrm{~nm}$ & $\begin{array}{c}W_{\mathrm{VRH}}, \mathrm{eV} \\
(T=120 \mathrm{~K})\end{array}$ & $\begin{array}{c}S, \mu \mathrm{V} / \mathrm{K} \\
(T=120 \mathrm{~K})\end{array}$ & $\begin{array}{c}\left(\frac{\partial \ln g(E)}{\partial E}\right)_{E=E_{F}}, \mathrm{eV}{ }^{-1} \\
(T=120 \mathrm{~K})\end{array}$ \\
\hline Исходное & 11.476 & $1.735 \cdot 10^{4}$ & $8.6 \cdot 10^{19}$ & 6.5 & 0.036 & 9.45 & 1.76 \\
После отжига & 8.426 & $5.041 \cdot 10^{3}$ & $2.9 \cdot 10^{20}$ & 4.8 & 0.026 & 6.17 & 2.14
\end{tabular}

$e-$ заряд электрона, $R$ - среднее расстояние прыжка, $v_{p h}-$ фактор спектра фононов взаимодействия, $T-$ абсолютная температура, $g\left(E_{F}\right)$ - плотность состояний на уровне Ферми, $a-$ радиус локализации волновой функции электрона, $k-$ постоянная Больцмана.

Из рис. 4, $a$ были определены значения величин $B$ для исследованных пленок. Предполагая, что процесс переноса носителей заряда лимитируется прыжками между оборванными связями углерода, для оценки плотности локализованных состояний принимаем радиус локализации равным Боровскому радиусу [28]

$$
a_{B}=\frac{\varepsilon_{0} \hbar^{2}}{m^{*} e^{2}},
$$

где $\varepsilon_{0}-$ статическая диэлектрическая проницаемость, $m^{*} \approx m_{0}-$ эффективная масса электрона, $e-$ заряд электрона. Для неупорядоченных углеродных материалов характерны значения $\varepsilon_{0} \approx 10$ [29], что дает $a_{B}=5 \mathrm{~nm}$. Тогда, применяя выражения (2)-(4), можно провести оценку параметров аморфной пленки углерода, исходя из модели прыжковой проводимости электронов с переменной длиной прыжка по локализованным состояниям, лежащим в узкой полосе энергий вблизи уровня Ферми (табл. 2).

Проведем также оценку средней энергии прыжка (табл. 2), которая в случае прыжков с переменной длиной прыжка должна быть равна

$$
W_{\mathrm{VRH}} \cong k\left(B T^{3}\right)^{1 / 4} .
$$

Если в исследованном интервале температур имеет место прыжковый механизм проводимости с переменной длиной прыжка по локализованным состояниям, лежащим в узкой полосе энергий вблизи уровня Ферми, то для термоэдс должно быть справедливо выражение [11]

$$
S=\frac{k^{2}}{2 e} \sqrt{T B}\left(\frac{\partial \ln g(E)}{\partial E}\right)_{E=E_{F}} .
$$

Учитывая полученные ранее значения $B$ и $S$, можно оценить производные логарифма плотности локализованных состояний по энергии для различных температур. Результаты таких оценок для исследованных пленок при $T=120 \mathrm{~K}$ представлены в табл. 2 .

Полученные значения плотности локализованных состояний находятся в полном согласии с результатами,

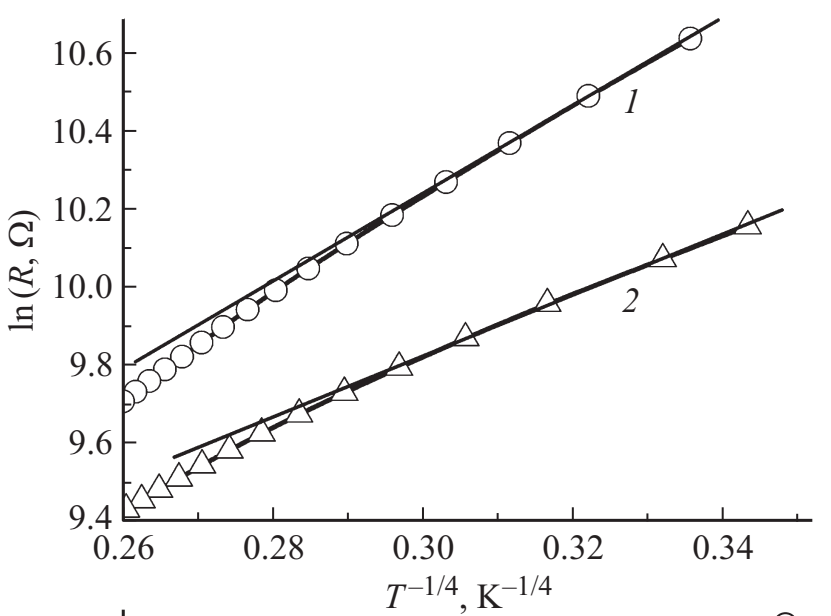

$a$

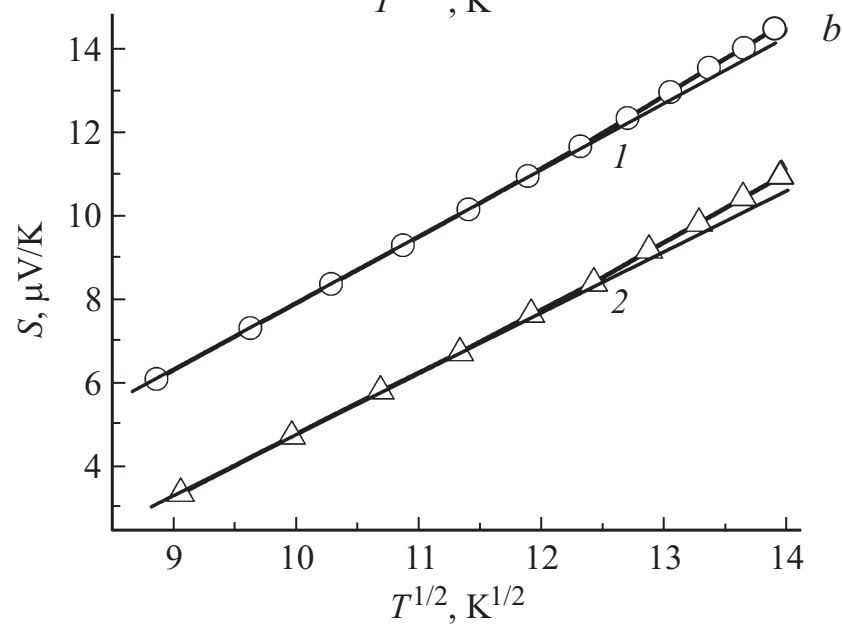

Рис. 4. Зависимости $\ln R \propto f\left(1 / T^{1 / 4}\right)$ (a) и $S \propto f(\sqrt{T})$ (b) тонких пленок аморфного углерода: кривая $1-$ исходное состояние, кривая 2 - после отжига в вакууме при $200^{\circ} \mathrm{C}$.

приведенными в [30-32]. Из данных табл. 2 также следует, что отжиг в вакууме при $200^{\circ} \mathrm{C}$ приводит к увеличению плотности локализованных состояний на уровне Ферми и ее производной по энергии вблизи уровня Ферми, а также к уменьшению энергии прыжка.

Для описания температурных зависимостей электрической проводимости в температурном интервале 130-190 К применим модель прыжковой проводимости по ближайшим соседям, тогда, согласно [11], для электросопротивления и термоэдс должны выполняться 
Таблица 3. Рассчитанные параметры для пленок аморфного углерода, определенные из модели прыжковой проводимости электронов по ближайшим соседям

\begin{tabular}{l|c|c|c|c}
\hline \multicolumn{1}{|c|}{ Состояние } & $\begin{array}{c}S, \mu \mathrm{V} / \mathrm{K} \\
(T=130 \mathrm{~K})\end{array}$ & $\begin{array}{c}\left(\frac{\partial \ln g(E)}{\partial E}\right)_{E=E_{F}}, \mathrm{eV}^{-1} \\
(T=130 \mathrm{~K})\end{array}$ & $\begin{array}{c}R_{0}, \mathrm{~nm} \\
(T=130 \mathrm{~K})\end{array}$ \\
\hline Исходное & 10.2 & 5.0 & 0.027 & 4.7 \\
После отжига & 6.9 & 3.4 & 0.019 & 3.5 \\
в вакууме $200^{\circ} \mathrm{C}$ & & &
\end{tabular}
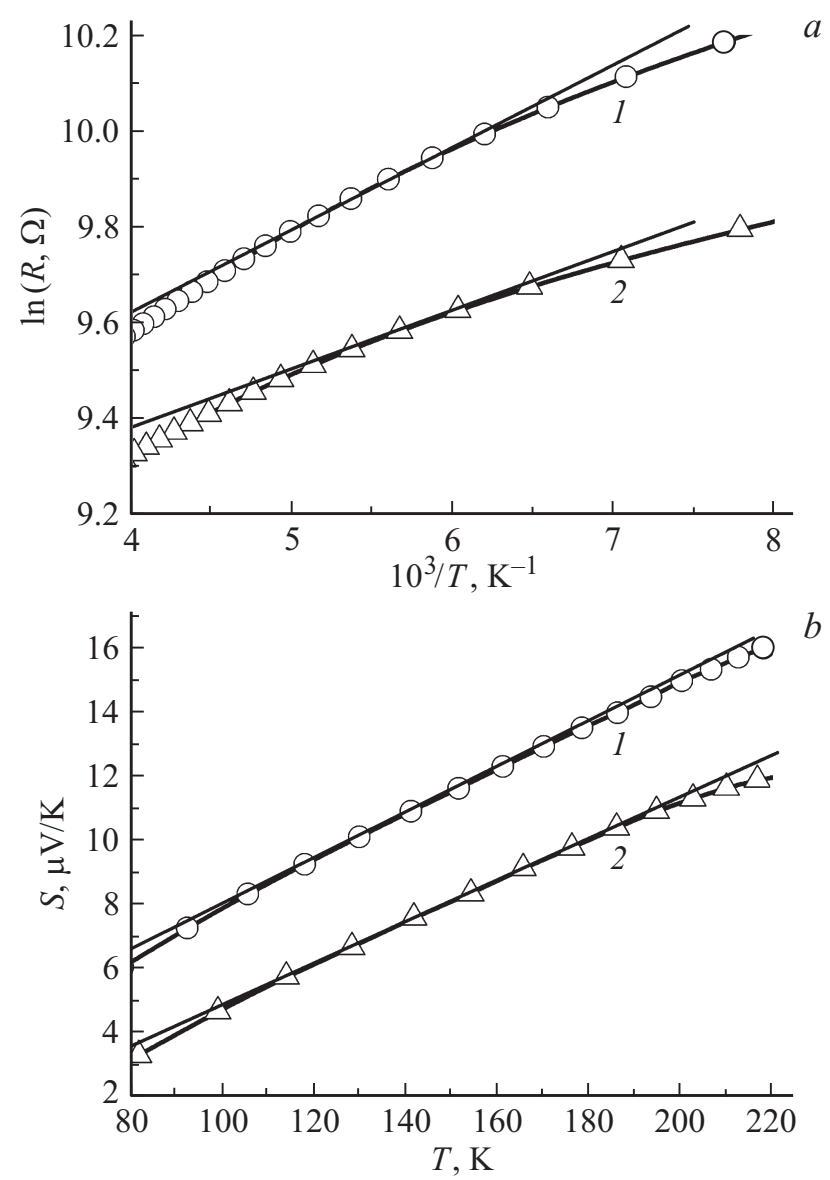

Рис. 5. Зависимости $\ln R \propto f(1000 / T)$ (a) и $S \propto f(T) \quad(b)$ тонких пленок аморфного углерода: кривая $1-$ исходное состояние, кривая 2 - после отжига в вакууме при $200^{\circ} \mathrm{C}$.

равенства

$$
\begin{gathered}
\rho=\rho_{1} \exp \left(-\frac{W_{\mathrm{NNH}}}{k T}\right), \\
S=\frac{2 \pi}{3} \frac{k^{2} T}{e}\left(\frac{\partial \ln g\left(E_{F}\right)}{\partial E}\right)_{E=E_{F}},
\end{gathered}
$$

где $W_{\mathrm{NNH}}$ - энергия активации прыжка, задаваемая для прыжков по ближайшим соседям выражением

$$
W_{\mathrm{NNH}}=\frac{3}{4 \pi R_{0}^{3} g\left(E_{F}\right)},
$$

где $R_{0}$ - среднее расстояние между ближайшими соседями, $g\left(E_{F}\right)$ - плотность состояний на уровне Ферми.
Используя формулы (7) и (8), из рис. 5, $a$ и $b$ оценим значения энергии активации прыжка и производные логарифма плотности локализованных состояний. Результаты приведены в табл. 3 .

В диапазоне температур 240-300 K зависимости удельного электрического сопротивления и термоэдс имеют линейные участки в координатах $\ln R \propto$ $\propto f(1000 / T)$ и $S \propto f(1000 / T)$. Тогда, если для температурных зависимостей термоэдс и удельного электрического сопротивления справедливы уравнения

$$
\rho=\rho_{0} \exp \left(-\frac{E_{a}^{R}}{2 k T}\right),
$$

где $E_{a}^{R}$ - энергия активации электрической проводимости, $k-$ постоянная Больцмана, $T-$ абсолютная температура,

$$
S= \pm \frac{k}{e}\left(\frac{E_{a}^{S}}{k T}+A\right),
$$

где $e-$ заряд электрона, $A-$ постоянная, $E_{a}^{S}-$ энергия активации термоэдс,

$$
\rho=\rho_{0} \exp \left(-\frac{E_{a}^{R^{*}}+W_{h}}{2 k T}\right),
$$

где $E_{a}^{R^{*}}=E_{a}^{S}=E_{A}-E_{F}, E_{A}$ - энергия на краю зоны проводимости, $E_{F}$ - энергия Ферми, и, учитывая уравнения (10)-(12), по экспериментальным зависимостям (рис. 6, $a$ и $b$ ) можно оценить значения энергии активации проводимости $E_{a}^{R}$ и термоэдс $E_{a}^{S}$. Результаты такой оценки приведены в табл. 4.

Значения энергии активации удельного электрического сопротивления больше значений энергии термоэдс, что указывает на то, что электроперенос осуществляется прыжками носителей в хвостах зон. Однако энергия активации термоэдс как для исходного состояния, так и после отжига очень мала и принимает значения, не

Таблица 4. Энергии активации проводимости и термоэдс тонких пленок аморфного углерода в области температур $240-300 \mathrm{~K}$

\begin{tabular}{l|c|c|c}
\hline \multicolumn{1}{c|}{ Состояние } & $E_{a}^{R^{*}}, \mathrm{eV}$ & $E_{a}^{S}, \mathrm{eV}$ & $W_{h}, \mathrm{eV}$ \\
\hline Исходное & 0.038 & 0.0065 & 0.0315 \\
После отжига в вакууме $200^{\circ} \mathrm{C}$ & 0.031 & 0.0052 & 0.0258
\end{tabular}



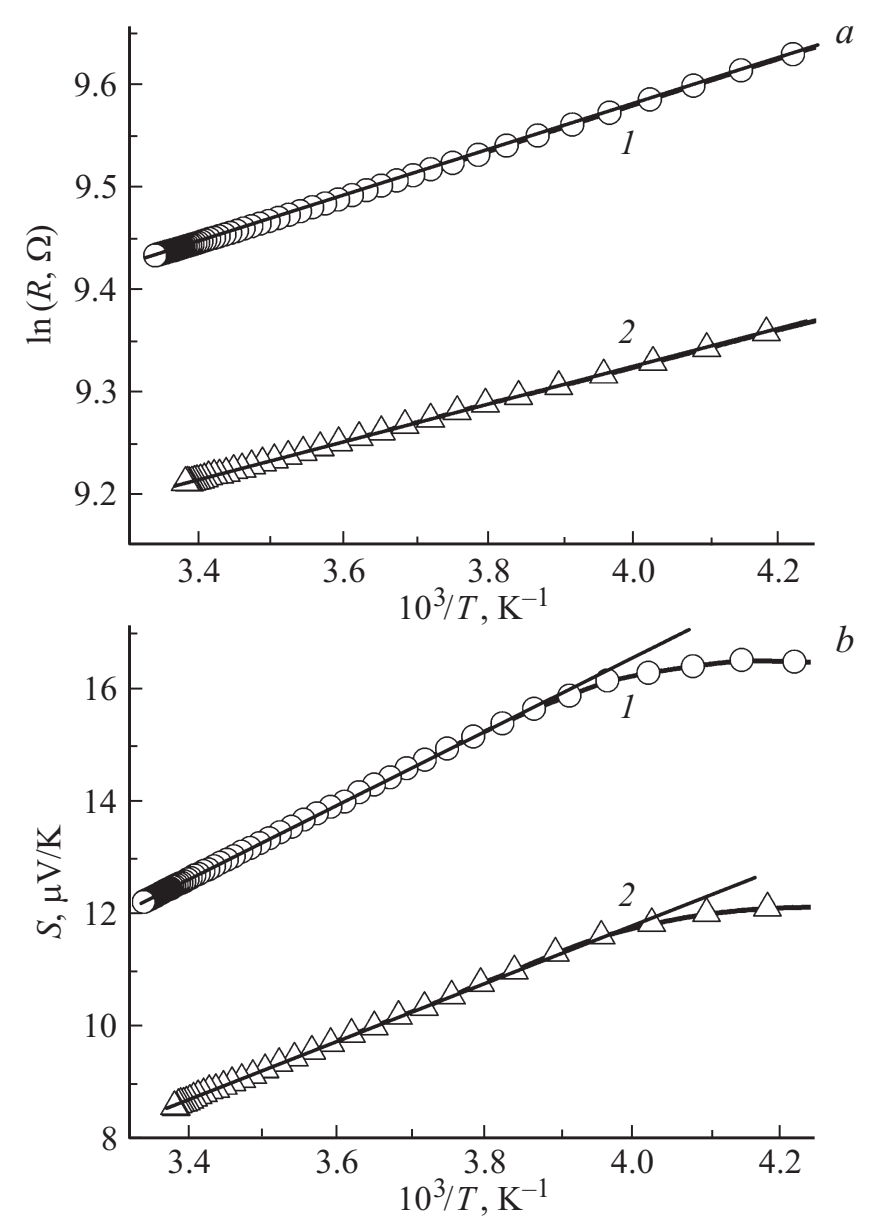

Рис. 6. Зависимости $\ln R \propto f(1000 / T)$ (a) и $S \propto f(1000 / T)(b)$ тонких пленок аморфного углерода: кривая 1 - исходное состояние, кривая 2 - после отжига в вакууме при $200^{\circ} \mathrm{C}$.

реалистичные с физической точки зрения. Это может быть объяснено тем, что указанная область температур является областью сосуществования нескольких равноценных механизмов электропереноса, и для корректной оценки энергии активации термоэдс и удельного электросопротивления эти вклады необходимо разделять.

В [33] авторы также пришли к выводу, что в области температур от комнатной и выше выражение для термоэдс можно описать суммой двух слагаемых: термически активированная прыжковая по хвостам зон и термоэдс, обусловленная $s p^{2}$-кластерами. Авторы предположили, что если термоэдс $s p^{2}$-кластеров можно описать выражением, характерным для термоэдс металлов, то результирующее значение термоэдс будет определяться как

$$
S(T)=S_{\text {metallic }}+S_{\text {hopping/activated }}=\frac{\pi^{2} k^{2} T}{3 e \mu(T)}+\frac{E_{\mathrm{act}}}{e T},
$$

где $k$ - постоянная Больцмана $\left(8.617 \cdot 10^{-5} \mathrm{eV} / \mathrm{K}\right), T$ температура, $e-$ заряд электрона, $\mu-$ химический потенциал, $E_{\text {act }}$ - энергия активации термоэдс при прыжковой проводимости в хвостах зон.
Похожий подход для описания температурной зависимости термоэдс в области средних и высоких температур был применен в [34], однако оценки значений химического потенциала дали нереалистичные значения: 5.9, 4.9, 15 и $3.7 \mathrm{eV}$ для тонких пленок аморфного углерода в исходном состоянии и после термообработки в вакууме в течение $30 \mathrm{~min}$ при температурах 400, 800,1300 и $1500^{\circ} \mathrm{C}$ соответственно. Авторы объяснили подобные нестыковки возможностью существования носителей тока со знаком, обратным знаку основных носителей, а также разбросом положения уровня Ферми между $s p^{2}$-кластерами.

\section{Заключение}

Методом ионно-лучевого распыления в среде аргона получены тонкие аморфные графитоподобные пленки углерода. Установлено, что для тонких пленок аморфного графитоподобного углерода наблюдается последовательная смена доминирующего механизма проводимости от прыжкового с переменной длиной прыжка в узкой полосе энергий вблизи уровня Ферми к прыжкам по ближайшим соседям, который сменяется прыжковым электропереносом с переменной длиной прыжка по локализованным состояниям в хвосте валентной зоны при температурах, близких к комнатной.

Авторы выражают благодарность руководителю ЦКП „Диагностика структуры и свойств наноматериалов“ НИЦ „БелГУ“ д.ф.-м.н. проф. О.Н. Иванову за исследования тонких пленок аморфного углерода методом рамановской спектроскопии.

Работа выполнена при поддержке Министерства образования и науки в рамках проектной части государственного задания (проект № 3.1867.2017/ПЧ).

\section{Список литературы}

[1] Джсонсер А.К., Хилл Р.М. // Физика тонких пленок. М.: Мир, 1978. С. 180-263.

[2] Grill A. // Diamond and Related Materials. 1999. Vol. 8. P. $428-434$.

[3] Peng X.L., Clyne T.W. // Thin Solid Films. 1998. Vol. 312. P. 207.

[4] Ivanov-Omskii V.I., Siklitsky V.I., Sitnikova A.A., Suvorova A.A., Tolmatchev A.V., Zvonariova T.K., Yastrebov S.G. // Phil. Mag. 1997. Vol. 76. P. 973.

[5] Robertson J. // Diam. Rel. Mat. 1992. P. 397-406.

[6] Robertson J. // Material Science Forum. 1989. Vol. 52\&53. P. $125-150$.

[7] Bubenzer A., Dischler B., Brandt G., Koidl P. // J. Appl. Phys. 1983. Vol. 54. P. 4590.

[8] Kaplan S., Jansen F., Machonkin M. // Appl. Phys. Lett. 1985. Vol. 47. P. 750

[9] Zou J.W., Reichelt K., Schmidt K., Dischler B. // J. Appl. Phys. 1989. Vol. 65. P. 3914.

[10] Robertson J. // Philosophical Magazine. Part B. 1990. Vol. 76. P. 335-350. 
[11] Мотm Н., Дэвис Э. Электронные процессы в некристаллических веществах: в 2 т. М.: Мир, 1982. Т. 1. 658 с.

[12] Moustafa S.H., Koos M., Pocsik I. // J. Non-crystalline Solid. 1998. Vol. 227-230. P. 1087-1091.

[13] Grill A. // Thin Sol. Film. 1999. Vol. 355-356. P. 189-193.

[14] Koos M. Moustafa S.H., Szilagyi E., Pocsik I. // Diamond and Related Materials. 1999. Vol. 8. P. 1919-1926.

[15] Clausing $R$. Diamond and Diamond-like Films and Coafings. NY: Plenum Press, 1991. 907 p.

[16] Mominzzaman Sh.M., Soga T., Jimbo T., Umeno M. // Diamond and Related Materials. 2001. Vol. 10. P. 1839-1842.

[17] Ferrari A.C., Robertson J. // Phys. Rev. B. 2000. Vol. 61. N 20. P 14095- 14107.

[18] Ferrari A.C., Kleinsorge B., Adamopoulos G., Robertson J., Milne W.I., Stolojan V., Brown L.M., Libassi A., Tanner B.K. // J. Non-Cryst. Sol. 2000. Vol. 266-269. P. 765-768.

[19] Schiffmann K. // Wear. 1988. Vol. 216. P. 27-34.

[20] Muto S., Kubo T., Kurokawa Y., Suzuki K. // Thin Sol. Film. 1998. Vol. 322. P. 233-238.

[21] Prikhodko O.Yu., Manabaev N.K., Guseynov N.R., Maksimova S.Ya., Mikhailova S.L., Daineko E.A. // Proc. „International Conference on Diamond and Carbon Materials (DIAM 2013)“. Italy, 2013. P. 96.

[22] Гриднев С.А. Калинин Ю.Е., Ситников А.В., Стогней $O . B$. Нелинейные явления в нано- и микрогетерогенных системах. М.: БИНОМ, Лаборатория знаний, 2012. $352 \mathrm{c}$.

[23] Сморгонская Э.А., Иванов-Омский В.И. // ФТП. 2005. Т. 39. Вып. 8. С. 970-975.

[24] Robertson J. // Mater. Sci. Engineer. R. 2002. Vol. 37. P. 129281.

[25] Ferrari A.C., Rodil S.E., Robertson J. // Phys. Rev. B. 2003. Vol. 67. P. 155306 (1-20).

[26] Сиклищкий В.И., Лущев Л.В., Байдакова М.В. // Письма в ЖТФ. 2002. Т. 28. Вып. 7. С. 46-51.

[27] Robertson J. // Philos. Mag. Lett. 1988. Vol. 57. P. 143.

[28] Каминский В.В., Васильев Л.Н., Романова М.В., Соловьев С.М. // ФТТ. 2001. Т. 43. Вып. 6. С. 997-999.

[29] Fung A.W.P., Wang Z.H., Dresselhaus M.S., Dresselhaus G., Pekala R.W., Endo M. // Phys. Rev. B. 1994. Vol. 49. P. 17325-17335.

[30] Maikena E.B., Taborek P. // J. Appl. Phys. 2000. Vol. 87. P. 4223.

[31] Shimakawa K., Miyake K. // Phys. Rev. 1989. Vol. 39. P. 7578.

[32] Meyerson B., Smith F.W. // Sol. Stat. Commun. 1982. Vol. 41. N 1. P. 23-27.

[33] Bhattacharyya S. // J. Phys. D: Appl. Phys. 2009. Vol. 42. P. 085407-085413.

[34] Takai K., Oga M., Sato H., Enoki T. // Phys. Rev. 2003. Vol. 67. P. 214202. 